\title{
Feasibility of Using Corncob as the Substrate for Natural Vinegar Fermentation with Physicochemical Changes during the Acetification Process
}

\author{
Kaustav Chakraborty, Joyjit Saha, Utpal Raychaudhuri, Runu Chakraborty* \\ Department of Food Technology and Biochemical Engineering, Jadavpur University, Kolkata, India \\ Email: ${ }^{*}$ crunu@hotmail.com
}

Received 15 July 2014; accepted 28 July 2015; published 31 July 2015

Copyright (C) 2015 by authors and Scientific Research Publishing Inc. This work is licensed under the Creative Commons Attribution International License (CC BY). http://creativecommons.org/licenses/by/4.0/

\section{(c) (i) Open Access}

\begin{abstract}
Vinegar made from corncob, an agricultural waste product of corn, is of interest in terms of its potential as a new functional condiment with physiological characteristics derived from polyphenols. The advent of food out of waste using lignocellulosic substrates is a modern biotechnological approach to enhance sustainability. The fermentation parameters for production of fermented vinegar from corncobs were optimized. The ethanolic fermentation was completed by Saccharomyces cerevisiae in 52 hours at $36^{\circ} \mathrm{C}$ producing $3.16 \%(\mathrm{v} / \mathrm{v})$ ethanol. The acetic acid fermentation was carried out by Acetobacter aceti in 48 hours at $34^{\circ} \mathrm{C}$ for producing vinegar having $3.91 \%(w / v)$ acetic acid. Total phenolic compound of corncob wine and vinegar was reported as $49 \mathrm{mg} / 100 \mathrm{ml}$ and $43 \mathrm{mg} / 100 \mathrm{ml}$ respectively. Total flavonoid content was determined to be about $12 \mathrm{mg} / 100 \mathrm{ml}$ of corncob wine and $9 \mathrm{mg} / 100 \mathrm{ml}$ of corncob vinegar. Corncob wine and vinegar showed highest antioxidant activity with $39 \%$ and $37.94 \%$ respectively. The structural change during the two step fermentation was also confirmed by scanning electron microscope (SEM). The Hunter color value of the corn cob vinegar was also evaluated. With the current trend of shifting to natural products, corncob vinegar with better health benefits and economic significance, certainly scores high above its synthetic counterpart.
\end{abstract}

\section{Keywords}

Corncob, Vinegar, Antioxidant, Color, SEM

\footnotetext{
"Corresponding author.
}

How to cite this paper: Chakraborty, K., Saha, J., Raychaudhuri, U. and Chakraborty, R. (2015) Feasibility of Using Corncob as the Substrate for Natural Vinegar Fermentation with Physicochemical Changes during the Acetification Process. Food and Nutrition Sciences, 6, 935-943. http://dx.doi.org/10.4236/fns.2015.610097 


\section{Introduction}

Vinegar, a weak form of acetic acid, is a versatile product that has been used in all corners of the world for over thousands of years as acidic seasoning by virtue of its physiological effects. Its acclivity in terms of use makes its study worthwhile. One of the prime qualities of vinegar to reduce $\mathrm{pH}$ aids in disinfection of food, processing equipment, neutralizes smell and prevents growth of pathogenic bacteria like Escherichia coli in food. It was also found that addition of vinegar to rice reduced glycemic index of rice by $20 \%-35 \%$ [1]. Natural vinegar is best known for its health values since ages. The vinegar available in the market is mostly synthetic that lacks any food or medicinal value. Natural vinegar could be obtained from different raw materials having good fermentation potential. Vinegar produced from different natural substrate have unique potential like plum vinegar have high antioxidant potential than red wine, black vinegar from brown rice have dihydrosinapic acid and rice shochu distilled vinegar shows strong LOOi-scavenging activity. Natural vinegar has long been used as a seasoning and preserving agent and is produced by a fermentation process from wine, apple juice, honey, rice, malted barley etc. In north eastern regions of Asia, such as China and Japan, vinegar is traditionally produced from cereals, primarily rice. Cereal or starch based source - natural vinegar is obtained by a three stage fermentation process [2]. Among the vinegar produced, alcohol vinegar accounts for the largest percentage, which is produced from diluted purified ethanol, but the interest for natural wine vinegars is now growing among the consumers. However, alternative processes have been extensively explored because of the high production cost associated with the utilization of natural fruit sources. Vinegar production from agricultural wastes could be a possible source because it has the potential to realize cheaper production of vinegar with low environmental impact by the effective utilization of renewable resources such as agricultural wastes. Among various agricultural wastes, corncobs are regarded as a promising agricultural resource because corn is widely cultivated and grown as choicest crop especially for its huge consumer acceptability and proteinaceous vegetable source. Utilization of waste in wine and vinegar production would go a long way in contributing considerably to the economy of emerging natural vinegar market. Corn is one of the major crops of India. The production of corn in India was $12,000,000 \mathrm{Mt}$ against the total world production of 602,026,822 Mt [3]. It is mainly used to produce glucose, fructose, high fructose corn syrups and other products. Corn cobs are mainly used as a fuel in furnaces or used as manure in the soil. The method of fermentation process has been identified as an economically viable option for conversion of these substrates to fermentation products, namely ethanol and xylitol. The conversion of glucose and xylose to ethanol by culture has been successfully obtained using a Saccharomyces cerevisiae. In the present study, projecting corncob vinegar as a suitable method for waste utilization economically, needs research in screening of variety of corn, suitable yeast strain and standardization of fermentation methods. The quality characteristics of the Corncob wine (CCW) and Corncob vinegar (CCV) were monitored during fermentation by measuring $\mathrm{pH}$, color and acidity. Of particular interest was the ability to retain antioxidant properties throughout the fermentation process. Total phenolic and flavonoid content and antioxidant (DPPH) properties of the Corncob wine and vinegar obtained were also profiled along with structural feasibility for fermentation and acetification by Scanning Electron Microscope (SEM).

\section{Material and Methods}

\subsection{Chemicals and Instruments}

Dextrose, $\mathrm{KH}_{2} \mathrm{PO}_{4}, \mathrm{~K}_{2} \mathrm{HPO}_{4}, \mathrm{MgSO}_{4} \cdot 7 \mathrm{H}_{2} \mathrm{O}, \mathrm{FeSO}_{4} \cdot 7 \mathrm{H}_{2} \mathrm{O}$, Urea, (Merck, India) were used. Yeast extract, Peptone (Himedia, India), 2,2-Diphenyl-1 picryl-hydrazyl (DPPH) (Himedia, India), Gallic acid (SD fine Chem Ltd India), Folin-Ciocalteu's phenol reagent (Merck India), $\mathrm{AlCl}_{3}$ (Merck India), $\mathrm{NaNO}_{2}$ (Merck India) were used. A Level $1 \mathrm{pH}$-meter with combined pH electrode (Elico, LI 120) with buffers of pH 3.0 and 7.0 was employed for the $\mathrm{pH}$ of corncob wine and vinegar samples. All the spectrophotometric analyses were implemented using a spectrophotometer (Hitachi U-2000). Quartz cuvettes with optical length of $10 \mathrm{~mm}$ were used. The following samples were subjected to research: Corncob wine (CCW) and Corncob vinegar (CCV). The corn cob was procured as agricultural waste from West Bengal, India.

\subsection{Alcoholic Fermentation}

Corn cob was washed with water and cut into pieces. They were pulped using mixer. After the above treatments, $30 \mathrm{~g}$ of the pulp sample and $70 \mathrm{ml}$ of distilled water were dispensed in $500 \mathrm{ml}$ conical flasks, plugged with cotton 
and placed on a rotary shaker for intimate mixing. The treated pulp sample obtained in this manner was then subjected to fermentation using stock culture of wine yeast Saccharomyces cerivisiae (NCIM 3315) procured from National Chemical Laboratory (NCL) Pune, India. The culture media consisted of 1.0 glucose, 0.3 malt extract, 0.3 yeast extract and 0.5 peptone all in $\mathrm{g} / 100 \mathrm{~mL}$. For the organisms to grow, the temperature was kept at $30^{\circ} \mathrm{C}$, pH 6.5 with a incubation period of 45 hours. The alcohol obtained was subjected for analysis of alcohol content using GC analysis. $5 \mathrm{~mL}$ of CCW sample was centrifuged (Remi C-24, Mumbai, India) at $3500 \mathrm{rpm}$ for 10 minutes. Gas Chromatography of supernatant was used to determine the ethanol concentration. Gas chromatography (GC) analysis was carried out using Agilent Technologies: GC system—7890A gas chromatography, column-Agilent JK WDB-624 with column ID-250 $\mu \mathrm{m}$, length-60 m and film length-1.4 $\mu \mathrm{m}$. The chromatograph was fitted with column $(28 \times 31 \times 16 \mathrm{~cm})$ with column gas flow rate $1.4615 \mathrm{ml} / \mathrm{min}$. Helium was used as a carrier gas and the solvent used is dimethyl sulfoxide (DMSO). The percentage of composition of the ethanol was calculated by the GC peak areas.

\subsection{Acetous Fermentation}

After fermentation, acetification was carried on using Acetobacter aceti to produce vinegar. Acetobacter aceti (NCIM 2116) was accomplished by inoculating on liquid medium, having the composition: 1.0 tryptone, 1.0 yeast extract, 1.0 glucose, 1.0 calcium carbonate, 2.0 agar g/100ml and incubating at $30^{\circ} \mathrm{C}$ for $48 \mathrm{~h}$ at $\mathrm{pH} 6.0$ with shaking for use as the vinegar starter in corncob wine after alcoholic fermentation. Acetic acid concentration formed by acetic fermentation was quantified by a HPLC system (JASCO, MD 2015 Plus, Multiwave length Detector) equipped with absorbance detectors set to $210 \mathrm{~nm}$. The column (ODS-3) was eluted with 0.01 (N) $\mathrm{H}_{2} \mathrm{SO}_{4}$ as the mobile phase at a flow rate of $0.5 \mathrm{~mL} / \mathrm{min}$ and a sample injection volume of $20 \mu \mathrm{L}$. Standard acetic acid (Merck, India) was used as an external standard.

\subsection{Total Phenol Content (TPC)}

The total phenolic content (TPC) for CCW and CCV were quantified using the Folin-Ciocalteu (FC) reagent was measured according to Di Stefano and Singleton method [4] [5]. A $150 \mu \mathrm{L}$ of Folin-Ciocatlteu reagent with aliquot of $20 \mu \mathrm{L}$ samples was taken in a spectrophotometer cuvette, $600 \mu \mathrm{L}$ of a $15 \% \mathrm{Na}_{2} \mathrm{CO}_{3}$ solution and distilled water were added to make the final volume of $3000 \mu \mathrm{L}$. The increase in absorbance was measured at 784 $\mathrm{nm}$. After 2 hours, the concentration of TPC was expressed as $\mathrm{mg} / 100 \mathrm{ml}$ gallic acid equivalent, determined by a calibration curve graph. Folin-Ciocalteu reagent could also be reactive with other chemicals in wine and vinegar, including thiols, inorganic ions, vitamin derivatives as well as amino acids. Therefore, although the result of FolinCiocalteu method represents a rough approximation of total phenolic content in most cases, compounds other than polyphenols need to be considered.

\subsection{Total Flavonoid Content}

The total flavonoid concentration was measured according to the method of [6]. Firstly $5.0 \% 75 \mu \mathrm{L}$ of $\mathrm{NaNO}_{2}$ was added, shortly followed by $10 \% 150 \mu \mathrm{L}$ of $\mathrm{AlCl}_{3} \cdot 6 \mathrm{H}_{2} \mathrm{O}$ and left for $5 \mathrm{~min}$. After adding $500 \mu \mathrm{L}$ of $\mathrm{NaOH}$, the absorbance was measured at $510 \mathrm{~nm}$. The total flavonoid content of samples was measured using a mg catechin equivalent of $100 \mathrm{~mL}$.

\subsection{DPPH Radical Scavenging Activity}

The effect of the extracted sample on DPPH radical was estimated according to the procedure described by Brand-William method [7]. The sample extract $(0.1 \mathrm{~mL})$ was added to $3.9 \mathrm{~mL}$ of DPPH $(100 \mu \mathrm{M})$ in ethanol that was prepared daily. After incubation time of $45 \mathrm{~min}$ the absorbance was determined at $515 \mathrm{~nm}$. Ethanol solution of $0.1 \mathrm{~mL}$ was used as blank and $3.9 \mathrm{~mL}$ of DPPH solution as control. The inhibitory percentage of DPPH was calculated according to the following Equation (1):

$$
\text { DPPH scavenging effect }(\%)=\left[1-\left(\text { absorbance }_{\text {sample }} / \text { absorbance }_{\text {control }}\right)\right] \times 100
$$

\subsection{Color Value}

Hunter colorimeter (Lab Scan XE, Hunter Associate Laboratories, Inc., Reston, VA) was used for the color 
measurements. By using illuminant $\mathrm{C}$ and $2^{\circ}$ observer angle, the sample was placed in a 1-cm path length optical glass cell in total transmission mode. The color parameters recorded were: $\left(L^{*}\right)$, $a^{*}$ value, $b^{*}$ value, chroma (saturation, $C^{*}$ ) and hue angle $\left(h^{\circ}\right)$.

\subsection{Scanning Electron Microscopy}

For the microscopic studies, samples of corncob and vinegar were freeze dried using a Lyophilizerand then transferred to a desiccator. After the samples were dehydrated, they were mounted over the stubs withdoublesided conductivity tape and were observed using a scanning electron microscope (model FEI Quanta -200 MK2) [8] at a specific magnifications of $800 \times$ and $3000 \times$.

\section{Results and Discussion}

\subsection{Factors Regulating the Production of Ethanol and Vinegar}

The fermentation parameters for production of fermented vinegar from corncobs were optimized. The ethanolic fermentation was completed by Saccharomyces cerevisiae in 52 hours at $36^{\circ} \mathrm{C}$ producing 3.16\% (v/v) ethanol. The acetic acid fermentation was carried out by Acetobacter aceti in 48 hours at $34^{\circ} \mathrm{C}$ for producing vinegar having 3.91\% (w/v) acetic acid. Glycolitic production of ethanol from glucose and fructose affects the subsequent acetic oxidation in different ways. In this study, the alcohol content of wine was analyzed using GC and found to be about $3.16 \%$ (Table 1) which was suitable for the acetic acid bacteria to produce acetic acid has been reported to be responsible for yeast-acetic acid bacteria antagonism in vinegar production [9]. However, in this case the alcohol content in vinegar was measured and found to be about $2.01 \%$; the drop in the alcohol content suggests the effective utilization of the sugar by the wine yeast due to alcoholic fermentation. On the contrary, acetic acid production can also be inhibited by low ethanol levels also due to increase of incomplete oxidation of polyols and sugars, mainly gluconic acid synthesis via direct glucose oxidation especially at low $\mathrm{pH}$ values [10]. The vinegar had a significant decrease of $57 \%$ which was more as compared to the reported $50 \%$ decrease of alcohol content in the jujube vinegar [11]. The drop in the alcohol content could due to conversion of alcohol content to acetic acid; the acetic acid (3.19\%) confirms the conversion [11]. The acids that may be present mainly in the wine are tartaric acid, tartarate, malic acid and potassium hydrogen mallate [12]. The increase in acidity in the vinegar was mainly due to acetic acid and other organic acids like citric acid, tartaric acid, succinic acid, lactic acid and gluconic acid etc. in minor amounts produced by Acetobacter aceti during acetification process during the study of the Balsamic and other vinegars [13]. Weak lipophilic acids with low pH posses a synergic effect which reduces intracellular $\mathrm{pH}$ of yeast below the normal physiological values, thereby inhibiting the yeast growth. So the $\mathrm{pH}$ was closely monitored having the mean values of 4.12 and 3.14 in wine and vinegar respectively, shown in Table 1 . As the titrable acidity increases, acetic acid seems to directly affect enzymatic activities, such as enolase, a key enzyme of glycolysis. The $\mathrm{pH}$ was found to be higher than the balsamic vinegar ( $\mathrm{pH}-2.2$ - 2.6) [13]. The decrease in $\mathrm{pH}$ in the vinegar was mainly due to increase in titrable acids like acetic acid and other organic acids. Fermentation temperature is an important parameter affecting yeast growth rate. The temperature in this study was kept at $30^{\circ} \mathrm{C}$ as yeasts are mesophilic organisms with an optimum growing temperature included between $20^{\circ} \mathrm{C}$ and $40^{\circ} \mathrm{C}$. When temperature decreases below $20^{\circ} \mathrm{C}$ in a wine fermentation, ethanol tolerance and growth rate of $S$. cerevisiae are greatly inhibited [14]. Exothermic metabolic reactions during the full-fermentation phase may raise the temperature above $40^{\circ} \mathrm{C}$, thus reducing the yeast vitality and ethanol yields causing undesirable stuck fermentations. So a constant monitoring was done to restrict the temperature to $30^{\circ} \mathrm{C}-32^{\circ} \mathrm{C}$.

In most cases of acetous fermentation, it is associated with a decrease in the parameters as far as studies till

Table 1. General composition of CCW and CCV.

\begin{tabular}{|c|c|c|c|c|c|c|}
\hline Sample & $\begin{array}{l}\text { Alcohol } \\
(\% \mathrm{v} / \mathrm{v})\end{array}$ & $\begin{array}{c}\text { Acetic acid } \\
\text { (g, \%) }\end{array}$ & $\mathbf{p H}$ & $\begin{array}{l}\text { Total phenols } \\
\text { (mg/100mL) }\end{array}$ & $\begin{array}{l}\text { Total flavonoids } \\
\text { (mg/100mL) }\end{array}$ & DРPH \% \\
\hline CCW & 3.16 & ND & 4.12 & 49 & 12 & 39 \\
\hline $\mathrm{CCV}$ & 2.01 & 3.91 & 3.14 & 43 & 9 & 37.94 \\
\hline
\end{tabular}

ND: not detected. All values are mean of three replications. 
date are considered. The individualistic reason for decrease has been provided below but one of the key factors of acetification changes, common to all parameters, is contributed by the type of container used in the acetification [15].

\subsection{Total Phenolic Content}

Polyphenols are the most abundant phytochemicals and characterization of the phenolic profile of vinegar is very important since the phenolic profiles of vinegars are responsible not only for their sensory characteristics but also for most of the health benefits attributed to them due to its antioxidant activity. Corncob wine and vinegar have been reported to have total polyphenol content of $49 \mathrm{mg} / 100 \mathrm{~mL}$ and $43 \mathrm{mg} / 100 \mathrm{~mL}$ respectively. However, it is the amount of extractable polyphenols as the portion of polyphenols bound to cell wall or trapped within the food matrix could not be determined [16]. The antioxidant activity of phenolic compounds is related to the hydroxyl groups linked to the aromatic ring, which are capable of donating hydrogen atoms with electrons and stabilizing free radicals. Recently, various health-promoting effects of vinegar like suppression of cardiovascular diseases and prevention of appetite increase along with increase in digestion absorption have been reported. These effects are assumed to be due to the phytochemicals in vinegar drinks, such as organic acid, amino acids, and phenolic compounds. Among them, polyphenol has high antioxidant activity [13]. The total polyphenol content of CCV is found to be higher than vinegars of Japanese apricot, apple and brown rice vinegar that have been reported to have relatively low polyphenol content below $25 \mathrm{mg} / 100 \mathrm{~mL}$ [17] and red ginseng vinegar (38.06 mg/100mL) [18]. But on the other hand the following vinegars: balsamic vinegar (372.53 mg/100mL), blackberry vinegar $(87.25 \mathrm{mg} / 100 \mathrm{~mL})$, pomegranate vinegar $(64.15 \mathrm{mg} / 100 \mathrm{~mL})$, cactus vinegar $(48.98 \mathrm{mg} /$ $100 \mathrm{~mL})$ and Red persimmon vinegar drink (60 mg/100mL) [18] had high amount of total polyphenol content than CCV. There are more than a thousand types of polyphenols among other products like green tea etc. Butprinciple compounds related to the vinegar phenolic content are gallic acid, a naturally abundant plant compound, derivatives and esters of benzoic acid, tartaric acid and cinnamic acid along with metabolic products of yeast, such as tyrosol [19]. CCW had a phenolic content of $49 \mathrm{mg} / 100 \mathrm{~mL}$ which decreased in the CCV to 43 $\mathrm{mg} / 100 \mathrm{~mL}$. The decrease in the phenolic content was in concord with the decrease in the total phenol content by acetification process which was highest for cider vinegar (40\%) and lower for red and white wine vinegars (13\% and $8 \%$ ) respectively [12]. The result reported in our study was about $12 \%$ which was alike of the red wine vinegars. The decrease in total phenolic content can be attributed to polymerisation or condensation reactions with other phenols, a similar phenomenon in vinous and berry substrates [20]. Accordingly CCV showed a decrease in the total phenolics content but the percent decrease was lower than cider vinegar and higher than white wine vinegars.

\subsection{Total Flavonoid Content}

Flavonoid is found in plant pigments that have flavones as a basic structure and occurs in plant leaves, roots, fruits, and stems. Flavonoids generally contain anthoxanthin, anthocyanin and catechin having antibacterial, anti-allergic and anti-inflammatory activities. Corncob wine and vinegar had a flavonoid content of $12 \mathrm{mg} /$ $100 \mathrm{~mL}$ and $9 \mathrm{mg} / 100 \mathrm{~mL}$ respectively. The content of flavonoids in corncob wine and vinegar is less correlated to their antioxidant capacity and has lower ratio flavonoids: polyphenols. It is similar with other vinegars like balsamic. Therefore, other compounds such as phenolic compounds different from flavonoids and Maillard reaction products, contribute to their antioxidant capacity. The flavonoid content of corncob vinegar was similar to $9.23 \mathrm{mg} / 100 \mathrm{~mL}$ found in the red ginseng vinegar and higher than cactus vinegar having flavonoid content below $5 \mathrm{mg} / 100 \mathrm{~mL}$. But the value is relatively low compared to fruit vinegars such as blackberry vinegar (51.12 mg/ $100 \mathrm{~mL}$ ) and others [18].

\subsection{Antioxidant Activity}

The DPPH free radical scavenging assay has been widely used to evaluate antioxidant capacities. Antioxidant properties of compounds present in corncob wine and vinegar are important as they retard or prevent oxidation process. The DPPH capacity of CCW and CCV are indicated in Table 1. Corn cob wine and vinegar obtained had a yellowish appearance. The antioxidant activity of CCW and CCV were evaluated using DPPH free radical-scavenging assays. In the DPPH assay, the DPPH of CCW and CCV were found to be $39 \%$ and $37.94 \%$, respectively. For production of vinegar using inoculated wines rather than spontaneous acetification process, was 
a contributing factor for a low antioxidant activity and high phenolic content in vinegar. This step was necessitated to maintain flavor profile by high phenolic content. However, the result was in accordance with previously reported results in the literature where the antioxidant activity of blueberry wine was higher than blueberry vinegar [21]. After acetic fermentation, the antioxidant activity of CCV was 37.94\%, which was higher than the one of balsamic vinegar [22]. Therefore, it could be concluded that the antioxidant activities of CCW and CCV though low, but was comparable to other wines and vinegars. The DPPH scavenging activity of the CCV and CCW was credited to the cumulative presence of higher concentration of polyphenols and other bioactive compounds. The result shows that vinegars are also free radical-scavengers, particularly of the peroxyl radicals, which are the major propagators of the oxidation chain of fat, thereby terminating the chain reaction [23]. The CCV showed high scavenging capacity higher than that of vinegars prepared pomegranate vinegar (5.63\%) and blackberry vinegar (12.07\%) [18]. However the reported radical-scavenging activity on DPPH radicals was less than that of the persimmon vinegars made from persimmon Saijo which showed the highest $(84.2 \% \pm 1.2 \%)$ but higher scavenging activity than vinegars from polished rice and apple which were found to be $13.5 \%$ and $11.2 \%$, respectively [24]. In our study, the vinegar was produced in laboratory scale involving glass vessel which usually displayed the lowest values for all the parameters than those produced in wood and oak barrels. Vinegars produced in oak and cherry barrel had highest amount of total phenols and antioxidants respectively as the stable anthocyanin-derived compounds are formed due to oxygen permeation through the wood thereby decreasing monomeric anthocyanins [15]. So the values reported in our study would certainly be enhanced if produced in pilot plants involving oak and cheery wood barrels.

\subsection{Hunter Color Parameters}

Color is an important aspect of wine and vinegar quality because of its relevance in sensory analysis and as an indicator of oxidation and aging processes. Rosy vinegar, for its special color and flavor, is very popular in the Southeast area of China [25]. Every winery producing high-quality vinegar standardizes its color so that it may serve to identify its brand. The coordinates $L^{*}, a^{*}, b^{*}$ determines the wine and vinegar color. At this scale, $L^{*}$ measures luminosity that varies from zero (black) to 100 (pure white); $a^{*}$ and $b^{*}$ values represent the levels of tonality and saturation, with $+a$ (indicating red), $-a$ (indicating green), $+b$ (indicating yellow) and $-b$ (indicating blue). According to the values in Table 2, the CCW and CCV was light ( $L^{*}$ value of 32.35 and 32.43 respectively). Both CCW and CCV are visually yellowish green in terms of color with values of $a^{*}(-4.19), b^{*}(11.19)$ for CCW and $a^{*}(-4.20), b^{*}(11.26)$ for CCV, as observed in this work. $C^{*}$ (Chroma) is a parameter that indicates the contribution of $a^{*}$ (redness) and $b^{*}$ (yellowness), respective values of Chroma for wine and vinegar are 11.94 and 12.01 respectively, with Hue angle (color, $\mathrm{h}^{\circ}$ ) of $69.54^{\circ}$ and $69.54^{\circ}$ respectively (Table 2). Overall, the CCW and CCV had a close approach to brewed vinegar, cider vinegar and brown rice vinegar [26]. The color of the wine and vinegar are reportedly same and color differences are small enough not to be noticed by eye (Table 2). As a final step in the production of sherry wine vinegars, color is adjusted before bottling by the addition of a small quantity of caramel, but however in our case it was not done. There is reportedly a strong correlation with the colour and antioxidant activity. Antioxidant activity of white wines to be markedly lower compared to the activity of red wines [27]. It was further confirmed that wines from berries being soft with a thin skin as well as light in color like cloudberries and strawberries had practically low antioxidant activity than from the wines from berries with strong color and relatively small size with a higher proportion of tough skin such as black currants, cranberries and crowberries, shown to exert high antioxidant activity [28]. With the yellowish green colour it is shown to have comparably high antioxidant activity as that of white wine vinegars.

\subsection{Scanning Electron Microscope (SEM) Studies on Structure Suitability of the Substrate}

Scanning electron microscopy of the corn cobs (in raw forms), before the cells adhesion (Figure 1(a) and

Table 2. Hunter color values of CCW and CCV.

\begin{tabular}{cccccc}
\hline Sample & L* $^{*}$ & $\mathbf{a}^{*}$ & $\mathbf{b}^{*}$ & \multicolumn{1}{c}{ Chroma (C) } & Hue angle \\
\hline CCW & 32.35 & -4.19 & 11.19 & 11.94 & $69.54^{\circ}$ \\
CCV & 32.43 & -4.20 & 11.26 & 12.01 \\
\hline
\end{tabular}

Chroma $(\mathrm{C})=\left[\left(a^{*}\right) 2+\left(b^{*}\right) 2\right]^{1 / 2}$ and hue angle $\left(h^{*}\right)=\arctan \left(b^{*} / a^{*}\right)$. Values presented are mean of duplicate analysis. 

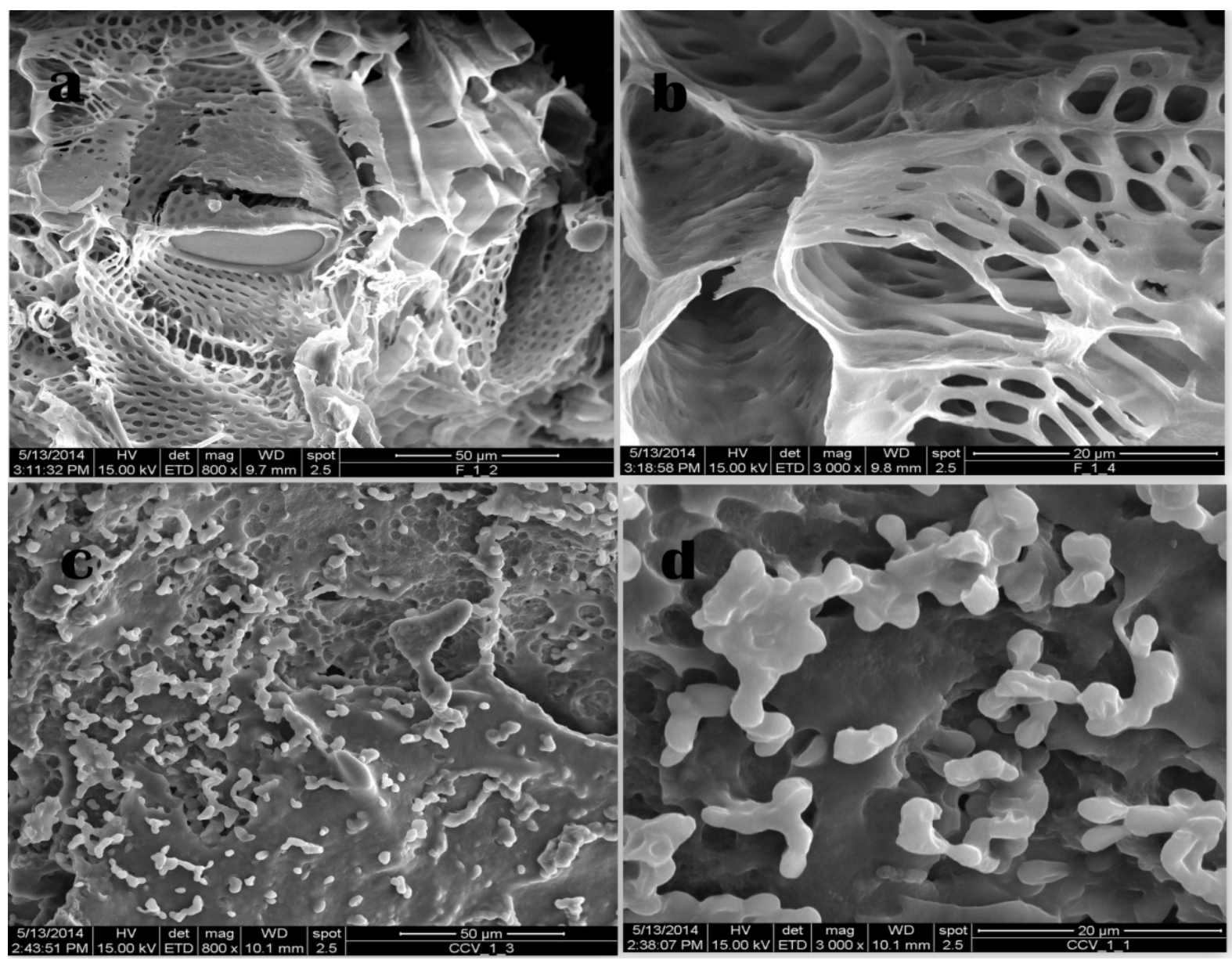

Figure 1. (a) SEM analysis of raw corncob substrate; (b) SEM analysis of raw corncob substrate (closer view); (c) SEM analysis of acetified corncob substrate fermented corncob substrate (Corncob vinegar); (d) SEM analysis of acetified corncob substrate fermented corncob substrate (Corncob vinegar) (closer view).

Figure 1(b)), revealed that fermentation and acetification did not occur in a homogeneous form on the material structure, but it was more favoured in specific region especially in rough and porous structures. In fact, such structures allow microorganisms, in this case yeast, to attach more firmly to the surface than the smooth structures. This phenomenon has also been reported in immobilization studies where corn cob was used successfully as a support material for the production of ethanol [29]. The yeast cells were attached on the materials surface by adhesion due to presence of a large number of cavities (Figure 1(a) and Figure 1(b)), which provided a natural entrapment of the cells (Figure 1(c) and Figure 1(d)), a phenomenon that is preferred in the beverage production. In brief, corn cobs were the most suitable support materials for adhesion of $S$. cerevisiae cells during fermentation. This may be due to the greater availability of nutrients (sugars and nitrogenous compounds) near the surface of the support. In addition, the greater nutrient availability in the cavities of is also an attraction to yeast cells, which encouraged yeast cells to migrate into the inner parenchyma cells during the process [30]. The appearance of the yeast cells was observed in the medium after fermentation and acetification (Figure 1(c) and Figure 1(d)). Adhesion of $S$. cerevisiae is essentially dependent upon electrostatic interactions between the support and the normally negatively charged cell surface and the attachment of the yeast cells on the support may have occurred as a result of hydrogen bonding, entrapment of the cells in corncob pieces, and the van der waal forces [30]. Because of this, corncob pieces are believed to have natural entrapment of yeast cells into the porous structure of said materials and due to physical adsorption by electrostatic forces between the cell membrane and the yeast cells. Similar results have been observed in yeast cells when using in apple pieces for wine preparations [8]. Therefore the structure of corncob is an important advantage considering the economy of the process and aids in more bioconversion of the masses to produce ethanol and acetic acid. 


\section{Conclusion}

Corncob vinegar was produced and its quality characteristics along with phytochemical contents were monitored during fermentation. During wine fermentation, highest alcohol yield was found to be 3.16\% and during acetic acid fermentation, acetic acid content was estimated to be $3.91 \%$. From wine fermentation to acetification, there was considerable change in alcohol content from $3.16 \%$ to $2.01 \%$ with a little change in pH. Vinegar produced from inoculated wine showed total phenolic content and antioxidant activity comparable to other wine vinegars. Physiochemical changes were assayed and found that all the parameters were decreasing from wine to vinegar involving total phenols decreasing from $49 \mathrm{mg} / 100 \mathrm{~mL}$ to $43 \mathrm{mg} / 100 \mathrm{~mL}$, antioxidants decreasing from $39 \%$ to $37.94 \%$ and the flavonoids from $12 \mathrm{mg} / 100 \mathrm{~mL}$ to $9 \mathrm{mg} / 100 \mathrm{~mL}$. The substrate feasibility was established by microscopic studies which entails an important factor for yeast and acetobacter fermentation. The results in this research indicate the possibility that corncob vinegar could be used as a new product with antioxidant activity that is comparable to other vinegar products.

\section{Acknowledgements}

This research work is financially supported by the "UGC-BSR Research Fellowship in Science for Meritorious Student” under University Grants Commission (UGC), India.

\section{References}

[1] Sugiyama, M., Tang, A.C., Wakaki, Y. and Koyama, W. (2003) Glycemic Index of Single and Mixed Meal Foods among Common Japanese Foods with White Rice as a Reference Food. European Journal of Clinical Nutrition, 57, 743-752. http://dx.doi.org/10.1038/sj.ejcn.1601606

[2] Wang, J. (2004) Preliminary Study on Traditional Technology of Zhejiang Rosy Vinegar. China Brew, 5, 23-26.

[3] FAO—Food and Agriculture Organisation of the United Nations (2002) FAOSTAT Statistics Database-Agriculture. Rome. www.fao.org

[4] Di-Stefano, R. and Guidoni, S. (1989) The Analysis of Total Phenols in Must and Wines. Vignevivni, 1, 47-52.

[5] Singleton, V.L., Orthofer, R. and Lamuela-Raventos, R.M. (1999) Analysis of Total Phenols and Other Oxidation Substrates and Antioxidants by Mean of Folin-Ciocalteu Reagent. Methods in Emzymology, 299, 152-178. http://dx.doi.org/10.1016/S0076-6879(99)99017-1

[6] Jia, Z., Tang, M. and Wu, J. (1999) The Determination of Flavonoid Contents in Mulberry and Their Scavenging Effects on Superoxide Radicals. Food Chemistry, 64, 555-559. http://dx.doi.org/10.1016/S0308-8146(98)00102-2

[7] Brand-Williams, W., Cuvelier, M.E. and Berset, C. (1995) Use of Free Radical Method to Evaluate Antioxidant Activity. LWT_Food Science and Technology, 28, 25-30. http://dx.doi.org/10.1016/S0023-6438(95)80008-5

[8] Kourkoutas, Y., Komaitis, M., Koutinas, A.A. and Kanellaki, M. (2001) Wine Production Using Yeast Immobilized on Apple Pieces at Low and Room Temperatures. Journal of Agricultural and Food Chemistry, 49, 1417-1425. http://dx.doi.org/10.1021/jf000942n

[9] Giudic, P. and Solieri, L. (2008) Yeasts Associated to Traditional Balsamic Vinegar: Ecological and Technological Features. Industrial Journal of Food Microbiology, 125, 36-45. http://dx.doi.org/10.1016/j.ijfoodmicro.2007.06.022

[10] Deppenmeier, U., Hoffmeister, M. and Prust, C. (2002) Biochemestry and Biotechnological Applications of Gluconobacter Strains. Applied Microbiology and Biotechnology, 60, 233-242. http://dx.doi.org/10.1007/s00253-002-1114-5

[11] Vithlani, V.A. and Patel, H.V. (2010) Production of Functional Vinegar from Indian Jujube (Zizyphusmauritiana) and Its Antioxidant Properties. Journal of Food Technology, 8, 143-149. http://dx.doi.org/10.3923/jftech.2010.143.149

[12] Andlauer, W., Stumpf, C. and Furst, P. (2000) Influence of Acetification Process on Phenolic Compounds. Journal of Agricultural and Food Chemistry, 48, 3533-3536. http://dx.doi.org/10.1021/jf000010j

[13] Masino, F., Chinnicib, F., Bendinic, A., Montevecchia, G. and Antonellia, A. (2008) A Study on Relationships among Chemical, Physical, and Qualitative Assessment in Traditional Balsamic Vinegar. Food Chemistry, 106, 90-95. http://dx.doi.org/10.1016/j.foodchem.2007.05.069

[14] Rainieri, S., Zambonelli, C., Hallsworth, J.E., Pulvirenti, A. and Giudici, P. (1998) Saccharomyces uvarum, a Distinct Group within Saccharomyces sensu stricto. FEMS Microbiology Letters, 177, 177-185. http://dx.doi.org/10.1111/j.1574-6968.1999.tb13729.x

[15] Cano-López, M., Pardo-Minguez, F., López-Roca, J.M. and Gómez-Plaza, E. (2006) Effect of Microoxygenation on Anthocyanin and Derived Pigment Content and Chromatic Characteristics of Red Wines. American Journal of Enology and Viticulture, 57, 325-331. 
[16] Maribel, O.M., Daglioglu, O., Guner, K.G., Gecgel, U. and Simsek, S. (2014) Analysis of the Fatty Acids and Phenolic Compounds in a Cereal-Based Fermented Food (Tarhana). Food and Nutrition Sciences, 5, 1177-1184. http://dx.doi.org/10.4236/fns.2014.513128

[17] Kim, G.R., Yoon, S.R., Lee, J.H., Yeo, S.H., Jeong, Y.J., Yoon, K.Y. and Kwon, J.H. (2010) Physicochemical Properties of and Volatile Components in Commercial Fruit Vinegar. Korean Journal of Food Preservation, 17, 616-624.

[18] Kim, S.H., Cho, H.K. and Shin, H.S. (2012) Physicochemical Properties and Antioxidant Activities of Commercial Vinegar Drinks in Korea. Food Science and Biotechnology, 21, 1729-1734. http://dx.doi.org/10.1007/s10068-012-0230-y

[19] Morales, M.L., Tesfaye, W., García-Parrilla, M.C., Casas, J.A. and Troncoso, A.M. (2001) Sherry Wine Vinegar: Physicochemical Changes during the Acetification Process. Journal of Agricultural and Food Chemistry, 81, 611-619. http://dx.doi.org/10.1002/jsfa.853

[20] Cerezo, A.B., Cuevas, E., Winterhalter, M., Garcia-Parrilla, M.C. and Troncoso, A.M. (2010) Anthocyanin Composition in Cabernet Sauvignon Red Wine Vinegar Obtained by Submerged Acetification. Food Research International, 43, 1577-1584. http://dx.doi.org/10.1016/j.foodres.2010.03.006

[21] Ubeda, C., Hidalgo, C., Torija, M.J., Mas, A., Troncoso, A.M. and Morales, M.L. (2011) Evaluation of Antioxidant Activity and Total Phenols Index in Persimmon Vinegars Produced by Different Processes. LWT-Food Science and Technology, 44, 1591-1596. http://dx.doi.org/10.1016/j.lwt.2011.03.001

[22] Lee, S.H. and Kim, J.C. (2009) A Comparative Analysis for Main Components Change during Natural Fermentation of Persimmon Vinegar. Journal of Korean Society of Food Science and Nutrition, 38, 372-376. http://dx.doi.org/10.3746/jkfn.2009.38.3.372

[23] Yen, G.C., Chang, Y.C. and Chen, J.P. (2002) Antioxidant Activity of Mycelia from Aspergillus candidus. Journal of Food Science, 67, 567-572. http://dx.doi.org/10.1111/j.1365-2621.2002.tb10639.x

[24] Sakanaka, S. and Ishihara, Y. (2008) Comparison of Antioxidant Properties of Persimmon Vinegar and Some Other Commercial Vinegars in Radical-Scavenging Assays and on Lipid Oxidation in Tuna Homogenates. Food Chemistry, 107, 739-744. http://dx.doi.org/10.1016/j.foodchem.2007.08.080

[25] Jiang, Y., Lin, S., Zhang, L. and Yu, P. (2013) Upgrading the Fermentation Process of Zhejiang Rosy Vinegar by Purebred Microorganisms. Advances in Microbiology, 3, 297-301. http://dx.doi.org/10.4236/aim.2013.33042

[26] Moon, S.Y., Chung, H.C. and Yoon, H.N. (1997) Comparative Analysis of Commercial Vinegar in Physicochemical Properties, Minor Components and Organoleptic Tastes. The Korean Journal of Food Preservation, 29, 663-670.

[27] Frankel, E.N. (1995) Natural and Biological Antioxidants in Foods and Biological Systems. Their Mechanisms of Action, Applications and Implications. Lipid Technology, 77-80.

[28] Heinonen, I.M., Lehtonen, P.J. and Hopia, A.I. (1998) Antioxidant Activity of Berry and Fruit Wines and Liquors. Journal of Agricultural and Food Chemistry, 46, 25-31. http://dx.doi.org/10.1021/jf970489o

[29] Genisheva, Z., Mussatto, S.I., Oliveira, J.M. and Teixeira, J.A. (2011) Evaluating the Potential of Wine-Making Residues and Corn Cobs as Support Materials for Cell Immobilization for Ethanol Production. Industrial Crops and Products, 34, 979-985. http://dx.doi.org/10.1016/j.indcrop.2011.03.006

[30] Reddy, L.V., Reddy, L.P., Wee, Y.J. and Reddy, O.V.S. (2011) Production and Characterization of Wine with Sugarcane Piece Immobilized Yeast Biocatalyst. Food Bioprocess Technology, 4, 142-148. http://dx.doi.org/10.1007/s11947-009-0321-9 